\title{
JURISDIÇÃO POLIVALENTE: NOVOS TEMPOS, VIRTUDES ANTIGAS
}

\section{POLYVALENT JURISDICTION: NEW TIMES, OLD VIRTUES}

\section{Bruno Makowiecky Salles ${ }^{1}$}

Resumo: Este artigo reúne reflexões sobre o exercício da Jurisdição em um contexto de Acesso à Justiça, de Judicialização e dos desafios qualitativos e quantitativos hoje existentes. Para tanto, fornece-se um panorama do cenário vigente e articulam-se aspectos do desempenho da Jurisdição com novos fatores como a crise do Positivismo jurídico, a aplicação de normas e os princípios constitucionais, o Ativismo e a Autocontenção e as funções cotidianas dos juízes. O objetivo é o de expor, com humildade científica, diretrizes que priorizem uma atuação técnica, criteriosa e ponderada dos juízes no ambiente democrático, dentro da antiga ideia de equilíbrio simbolizada na balança da justiça.

Palavras-chave: Jurisdição. Acesso à Justiça. Judicialização. Ativismo Judicial.

Abstract: This article brings reflections on the exercise of Jurisdiction in a context of Access to Justice, Judicialization and the currently existing qualitative and quantitative challenges. To this end, an overview of the current scenario is providedand, subsequently, aspects of the exercise of the Jurisdiction are articulated with new factors such as the crisis of Positivism, the application of constitutional rules and principles, Judicial Activism and Self-restraint and the functions of the judges. The

1. Pós-Doutorando em Ciência Jurídica pela Universidade do Vale do Itajaí (UNIVALI), com estágio pós-doutoral na Delaware Law School - WidenerUniversity. Doutor em Ciência Jurídica pela Universidade do Vale do Itajaí(UNIVALI). Dottore di Ricercain Scienze Giuridiche pela Università Degli Studi di Perugia - UNIPG, Itália (2019). Exerce o cargo de Juiz de Direito no Estado de Santa Catarina (2009). CV: http://lattes.cnpq.br/7479543022697803. E-mail: brunomakosalles@terra.com.br 
objective is to expose, with scientific humility, guidelines that prioritize technical, judicious and thoughtful performance by judges in the democratic environment, within the old idea of balance.

Keywords: Jurisdiction. Access to Justice. Judicialization. Judicial Activism.

\section{INTRODUÇÃO}

Os movimentos do Acesso à Justiça, impulsionados sobretudo na década de 1970 do século XX, e o fenômeno da Judicialização, exponenciado a partir dos anos de 1990 do mesmo século, contribuíram para projetar na Jurisdição na sociedade complexa um arco-íris de novas expectativas, encargos e possibilidades, intensificando desafios de ordem qualitativa e quantitativa.

O presente artigo reúne reflexões sobre o exercício da Jurisdição no contexto anteriormente referido. Para tanto, inicia-se fornecendo um retrato do atual panorama. Na sequência, articulam-se aspectos do desempenho da Jurisdição, em tal panorama, com fatores como a crise do Positivismo jurídico, a aplicação de normas e princípios constitucionais, o Ativismo e a Autocontenção Judiciais e as funções cotidianas dos juízes.

O objetivo do texto, longe de fornecer roteiros ou lições pretensiosas, é o de compartilhar, com humildade científica, algumas diretrizes soltas que priorizam uma atuação técnica, criteriosa e ponderada dos juízes no atual ambiente democrático, dentro da antiga ideia de equilíbrio, simbolizada na balança da justiça.

Relativamente à metodologia, cabe o registro de que, na fase de investigação, foi utilizado o método indutivo. Na fase de tratamento de dados, empregou-se o método cartesiano. Por fim, o texto foi composto sob a base lógica indutiva. As diversas fases da pesquisa foram auxiliadas com recurso a técnicas do referente, categoria, conceito operacional e pesquisa bibliográfica (PASOLD, 2015).

\section{UM PANORAMA}


Embalada pelos movimentos de Acesso à Justiça (CAPPELLETTI, 1979, p. 53-60), a presença do Poder Judiciário intensificou-se nas democracias ocidentais a partirda década de 1970 do século XX. O standard metodológico dominante em tais movimentos consiste em identificar óbices de acessibilidade ao Judiciário e aos Direitos para prescrever soluções voltadas a rZZemover tais óbices (FRIEDMAN, 1994, p. 21). Somada a outros fatores, semelhante concepção pavimentou uma larga avenida rumo ao Judiciário.

Na mesma direção, especialmente da década de 1990 em diante, testemunhou-se o fenômeno da Judicialização, que envolve a ideia de conferir a algo a forma de um processo judicial (VALLINDER, 1995, p. 13), seja mediantea transferência ao Judiciário de assuntos tradicionalmente decididos pelos Poderes Legislativo e Executivo, seja com a incorporação, por tais Poderes, de métodos decisórios, maneiras de agir, habilidades e conhecimentos próprios do Judiciário (TATE, 1995, p. 28).

$\mathrm{Na}$ atual quadra histórica, verifica-se uma onda de Judicialização que engloba desde questões de vida ou morte até trivialidades cotidianas. Trata-se de um fenômeno multicausal ligado às peculiares interações entre direito e política. Por meio dele, o Judiciário é recorrentemente instado a decidir macroquestões e microquestões potencializadas pela repetição. Ao fornecer respostas criativas não dadas pelos demais agentes ou consideradas inidôneas e submetidas à reanálise judicial, o Judiciário expande tanto $(\boldsymbol{i})$ o escopo das decisões judiciais quanto (ii) os métodos judiciais de tomada de decisão para a esfera política classicamente reservada aos demais Poderes (SALLES, 2021).

Tal dinâmica é turbinada nas Sociedades Complexas contemporâneas. Nelas convivem cenários antagônicos, como tradicionalismo e pós-modernidade, miséria e consumismo, produção primária e desenvolvimento tecnológico, analfabetismo e sofisticação intelectual (CÁRCOVA, 1996, p. 144). Vive-se um choque entre realidades no qual múltiplos discursos se entrecruzam, inclusive no ciberespaço. A massificação torna-se regra, a pessoalidade se dissipa e as distâncias são reduzidas pela tecnologia e superadas pela velocidade, gerando uma sensação coletiva 
de imediatismo "em que tudo é instantâneo" e a "morosidade", seja do que for, "é sentida de forma especialmente dolorosa" (GUEDES, 2009, p. 36). As tensões entre os sistemas social, econômico e político, associadas às estruturas de poder, ao primado da economia, ao ritmo célere da vida e à revolução tecnológica intensificam conflitos de distintos matizes, levando a juízo macro e microquestões.

Os movimentos do Acesso à Justiça e a Judicialização, alinhados e avolumadosnas sociedades complexas nos anos que lhes seguiram (SALLES, 2016, p. 277-305), forjaram novos desafios à magistratura, tantono planoqualitativo como noquantitativo. Afirma-se, inclusive, que "a explosão dos contenciosos transformou silenciosamente o acto de julgar, a tal ponto que já não se sabe muito bem qual foi o mais determinante, se o desafio quantitativo ou o desafio qualitativo" (GARAPON, 1998, p. 255) hoje existentes.

Do ponto de vistaqualitativo, os juízes passaram a ser crescentemente acionados para solucionar problemas cotidianos e hard cases $^{2}$ variados. Temas ambientais, bioéticos, carcerários, científicos, comerciais, criminais, culturais, econômicos, educacionais, étnicos, familiares, humanitários, imigracionais, infanto-juvenis, morais, políticos, religiosos, sanitários, tecnológicos, urbanísticos, bem como sobre questões de federalismo, liberdades individuais, terrorismo, privacidade e outras são submetidas à decisão judicial antes mesmo, em certas ocasiões, de um pronunciamento dos ramos governamentais. Postula-se, amiúde com base em princípios e normas abertas,que os juízes atuem ativamente, desempenhando papéis de outros Poderese/ou inovandoem sentidos e na criação do direito e de políticas públicas. Paradoxalmente, vilaniza-se o que quer que se considere Ativismo Judicial, sobretudo quando o conteúdo da decisão desagrada o censor (ROOSEVELT III, 2006, p. 3), seja ele conservador ou progressista. E, nessa interação, quanto maiores

2. Casos difíceis são aqueles nos quais, por força do grau de incompletude que sempre haverá nos ordenamentos jurídicos, ou da incapacidade de o legislador antecipar todas as situações, inexiste uma solução jurídica clara na lei ou nos precedentes, gerando dificuldade de decisão. 
os níveis de Ativismo, maiores os incentivosà Judicialização (TATE, 1995, p. 33), num ciclo que se retroalimenta.

Sob a perspectiva quantitativa, a avalanche de ações é sentida de formamarcadamenteimpactante, numa realidade quase autoevidente. Qualquer um que atue no cotidiano forense percebe-a via empirismo, e mesmo quem não vivencia o dia a dia das Cortes pode visualizá-la. Em razão disso, torna-se desnecessária a exposição de dados estatísticos, facilmente encontráveis alhures (CNJ, 2020; CEPEF, 2014; USC, 2018). O que importa aqui é a ideia de que "Litigation hás gonetotally out ofcontrol", mostrando-se, às vezes, epidêmica (FEIEDMAN, 1994, p. 9) e causando demora e incertezas que fazem do processo judicial “blacklogged” (HAZARD JR., 1986, p. 271), isto é, lento e incerto.

É importante notar que a Judicialização e a intensa litigiosidade dizem respeito não apenas ao controle de constitucionalidade e às ações coletivas de vasta repercussão, mas também a lides individuais variadas, de direito público ou privado, relevantes ou não, e a microquestões que, deduzidas em massa e potencializadas pela repetição, acabam ostentando impactos em atividades políticas (SHAPIRO, 1995, p. 57) e regulatórias. Deve-se lembrar que os desafios da jurisdição não moram unicamente nos casos difíceis (hard cases) objeto de discussão pública (ALLARD; GARAPON, 2005, p. 24) ou que ofereçam dificuldades na resolução fático-jurídica, embora tais espécies de casos assumam maior notoriedade e atenção. Eles radicam também em um número maior e silencioso de situações cotidianas, cujas decisões são tomadas com urgência, no improviso, automatizadas, sem luxos ou preocupações teóricas (GARAPON, 1998, p. 172), mas cujo volume suscita o congestionamento do sistema.

Pressionados por uma miríade de demandas, os sistemas jurídicos e a magistratura, na busca por resultados, incorporam novos componentespara o contexto da Jurisdição. Em sua essência, a Jurisdição é tida como a atividade própria do Estado mediante a qual as normas jurídicas, vazadas em regras ou em princípios, são aplicadas por juízes para a composição de conflitos subjetivos ou normativos com força de coisa julgada, compreendendo a dicção do direito e eventualmente sua exe- 
cução (SALLES, 2021b). Agora, vêm sendo entronizadas no dia a dia da magistratura, além de algumas tipologias de reformas em sistemas judiciais $^{3}$, soluções como a adoção de modelos gerenciais voltados a processos e pessoas, o fomento às autocomposições em juízo, as análises jurimétricas, o avanço da inteligência artificial (SALLES, 2020, p. 70-95), entre outros.

Referidos componentes são importantes e contribuem para a eficiência dos sistemas de justiça. Contudo, inviável descurar alguns de seus reflexos questionáveis a fortalecer a máxima de que quase tudo na vida apresenta duas ou mais facetas.

A natureza e a quantidade das questões Judicializadas indicam, enfim, que, por diversas causas que não cabe aqui aprofundar, o Judiciário expandiu-se como locus de reivindicação. Passaram a lhe ser direcionadas expectativas e competências decisórias em setores cada vez mais vastos das demandas sociais, convolando-o em "um espaço de exigibilidade da democracia" (GARAPON, 1998, p. 46), de correção de legislações e de oposição política. Como consequência, o juiz deixou de atuar em sua função técnica de dizer o direito, de agir como julgador de relações jurídicas concretas, controlador de constitucionalidade ou mediador institucional das relações políticas, para passar a ser considerado um árbitro dos bons costumes e da moralidade política, investido, por vezes, em funções clericais e paternais, agindo ainda como o gestor, "o conciliador, o apaziguador das relações sociais e até mesmo o animador de uma política pública"(GARAPON, 1998, p. 20).

Diante da diversidade dos assuntos que lhe são submetidos e da necessidade de solucioná-los adequadamente, o juiz da atualidade vem sendo:

[...] obrigado a dotar-se de uma personalidade multifacetada, já que é diretamente chamado a se mover em um mundo, da densa teia de leis, agora pulverizado. Deve, portanto, ser, de acordo com a época

3. São exemplos o (i) aumento dos recursos destinados aos juízes e à estrutura e criação de Tribunais, a (ii) modificação da atuação judicial e dos processos, a (iii) tentativa de redução do número das ações que ingressam no sistema, ou, ainda, a (iv) combinação desses elementos. 
e as circunstâncias, um juiz legislador, um juiz mediador, um juiz administrador, um juiz herói, um juiz controlador, um juiz operador social e assim por diante. (Tradução livre) ${ }^{4}$ CERETTI; GIASANTI, 1996, p. 10).

A polivalência que se exige da magistratura não pode vir desacompanhada, todavia, de questionamentos sobre que postura os juízes devem assumir em face do que deles se reclama, da vastidão das demandas que lhes são endereçadas e da possibilidade ou não de atenderem a essas demandas à luz dos papéis e limites assinalados à função judicial no regime democrático. As linhas que seguem trazem algumas ponderações, sem qualquer pretensão de exaurimento sobre essa complexa e delicada temática, além de possíveis reflexões sobre o exercício da magistratura no instável cenário contemporâneo.

\section{REFLEXÕES COMPARTILHADAS}

As circunstâncias destacadas até aqui projetam, na Jurisdição, um arco-íris de novas expectativas e possibilidades, que precisam ser bem equacionadas pela magistratura. Além disso, e já avançando em especificidades, elas permitem sustentar a defasagem, em largas bases, da aplicação judicial do direito baseada no paradigma do positivismo jurídico (RADBRUCH, 1959, p. 183), afirmação que vale para o positivismo exegético, para o positivismo normativista e também para versões do neopositivismo (BOBBIO, 1995, p. 25-112). Entre outros aspectos, elas ainda provocam meditações no que se refere à aplicação de normas constitucionais e princípios jurídicos, ao Ativismo Judicial e às atribuições dos juízes no cotidiano, como se passa a expor em breves linhas.

Em relação ao paradigma positivista (ZANON JÚNIOR, 2014, p. 229-230) ${ }^{5}$, tem-se que o espaço ocupado pelas normas-princípio (ALE-

4. Do original: [...] costretto a dotarsidi una personalitàpoliedrica in quanto èchiamatodirettamente a muoversi in un mondo, quellodellafitta trama delleleggi, cheèormaipolverizzato. EgliDovràCosiEssere, secondo i tempi e lecircostanze, giudicelegislatore, giudicemediatore, giudiceamministratore, giudiceeroe, giudicecontrollore, giudiceoperatoresocieale e cosi via.

5. Essa referência contém conceito bastante fiel do Positivismo Jurídico. 
XY, 2008, p. 88; e DWORKIN, 2011, p. 39-42) e pelas técnicas de ponderação debilita a preponderância das normas-regra e a lógica da subsunção. A ficção de completude de um ordenamento jurídico dotado de normas a serem meramente aplicadas torna-se surreal perante a velocidade das demandas sociais, econômicas e tecnológicas, que não aguardam o tempo do processo legislativo. A busca por padrões jurídicos para a resolução dos casos difíceis substitui a defesa da discricionariedade judicial. Dá-se, ainda, uma constante penetração da moral e da política nas lides jurídicas. Todos esses aspectos abalam as fundações positivistas (ZANON JÚNIOR, 2014, p. 89-122). Soma-se a eles a crescente sofisticação de técnicas de controle de constitucionalidade, como as sentenças manipulativas e aditivas, o instituto do apelo ao legislador, a interpretação conforme a Constituição com ou sem redução de texto, a modulação temporal dos efeitos da decisão (SEGADO, 2011, p. 128; e BARROSO; MELLO, 2019, p. 295-334), além de outros leques de opções que fazem obsoleta a concepção de Judiciário como legislador meramente negativo.

É certo que essa conjuntura não legitima um retorno ao Jusnaturalismo, àquela ordem universal de valores metafísicos ou resultantes da razão (KELSEN, 2001, p. 21) que, aplicáveis a todos os tempos e lugares, se impregnam de uma carga tal de subjetividade que mina a certeza do direito. Todavia, ela encoraja os juízes a um passo adiante na direção do Pós-positivismo, o qual, entre outras coisas, valoriza o papel da ponderação e dos princípios, objetiva reduzir a discricionariedade, não encara o direito como um produto acabado com normas já postas (ATIENZA, 2013, p. 29) e reconhece um grau de indeterminação e certa abertura nos conteúdos da Constituição (LEAL, 2007, p. 95-96), a pressupor atitudes interpretativas diferentes.

Entre as principais correntes pós-positivistas, situam-se o substancialismo, o procedimentalismo e o pragmatismo, que convivem, ainda, com importantes teorias dialógicas como os diálogos institucionais e o minimalismo judicial (SALLES, 2021b). Trata-se de aportes teóricos fundamentais, que auxiliam os juízes nos desafios dos novos tempos e 
nas discussões atuais sobre os limites e as possibilidades de suas atuações em regimes democráticos (SALLES, 2021b).

A adjudicação baseada em normas constitucionais deve partir do pressuposto de que a Constituição não impõe projetos políticos prontos, senão desenhos que devem ser coloridos de modo plural na democracia (ZAGREBELSKY, 2003, p. 12-14). A Constituição não se acha sob monopólio judicial, possuindo a intepretação e a concretização abertas aos demais órgãos estatais, cidadãos e grupos na sociedade (HABERLE, 2002). Assim, mostra-se curial aos juízes ao exercerem o controle de validade da legislação infraconstitucional e das políticas públicas, tendo em conta certo grau de deferência à liberdade de conformação dos demais ramos. Similarmente, ao aplicarem as normas constitucionais de maneira direta, é prudente que observem a taxonomia e o nível de eficácia de tais normas (AFONSO DA SILVA, 1998, p. 126), aferidas a partir da estrutura redacional, da matéria versada e das condições fáticas subjacentes à previsão abstrata. Isso tudo sem prejuízo da força normativa da Constituição (HESSE, 1991) e do necessário dever de responsividade (NONET; SELZNICK, 2010, p. 55), cabendo-lhes balancear os elementos dessa difícil equação.

Quanto aos princípios jurídicos, sabe-se que, entre outras funções e ao lado de sua carga de abstração, eles exercem o papel de atribuir aos fatos um valor normativo próprio. Os princípios como que sinergizam norma e fato. Ao entrarem em contato com os princípios, os fatos (ser) adquirem vida e valor, conduzindo a uma tomada de posição jurídica (dever ser) por parte do juiz, o que aproxima a aplicação do direito do caso concreto, mitigando a prevalência de abstrações (ZAGREBELSKY, 2003, p. 122). Significa que os princípios guiam, orientam, conduzem e fecham a interpretação do direito face a face com o fato. Tal concepção, como se vê, em nada é compatível com uma principiologia fundada em slogans vagos, na qual um princípio é utilizado como artifício retórico para, como mecanismo de abertura e em desatenção ao seu conteúdo nuclear, justificar uma solução preferencial qualquer. Tampouco é consentânea com a invenção de um cipoal de princípios, 
conferindo-se tal distinção a valores ou máximas que não exercem uma função constitutiva da ordem e dos institutos jurídicos.

A aplicação e a ponderação dos princípios estão longe de traduzir tarefas puramente subjetivas. Elas observam um dever de coerência e integridade (DWORKIN, 2007, p. 203), condicionando-se à avaliação de aspectos fáticos e normativos e ao estudo doutrinário. A dogmática pode auxiliar na tarefa, por meio de descrição da norma ou do conteúdo do princípio, da submissão a uma análise conceitual e sistemática e da proposição de uma solução para o problema jurídico. Em especial, a tabulação de precedentes exerce papel determinante para que se criem parâmetros sobre o conteúdo, a extensão e o emprego dos princípios em casos análogos. Embora seja difícil, nas lides cotidianas, seguir fórmulas matemáticas (ALEXY, 2015, p. 15), daí não se justifica o extremo oposto de uma ponderação ad hoc ou discricionária, seletiva, apartada do sentido do ordenamento. Uma decisão judicial consistente deve permear-se por toda essa consciência, necessariamente observando, quanto aos fatos e ao direito, um dever de fundamentação (SUNSTEIN, 2001, p. 31$)^{6}$ que a legitime e lhe confira racionalidade.

Seriaumequívoco pensar, em todo esse contexto, que a Judicialização, o Pós-positivismo, os princípios, as normas abertas e as novas técnicas de controle jurisdicional endossam uma espécie de cheque em branco ao Ativismo Judicial, seja no plano substancial, seja no plano processual. Por outro lado, e em sentido inverso, a utilização dolosa ou mal-intencionada da expressão Ativismo não há de incutir nos juízes uma eficácia intimidatória, ressuscitando a mitologia de que atuam como mera boca da lei.

Em rigor, o Ativismo Judicial reflete uma atitude jurisdicional de tendências transformadoras, mais que contemplativas, que se manifestam (stricto sensu), conjunta ou isoladamente, nos âmbitos (i) interpretativo ou aplicativo, mediante um acentuado voluntarismo na criação do direito em detrimento da legislação, de precedentes ou de padrões jurídicos

6. A exigência de fundamentação incrementa a qualidade das decisões e reduz a discricionariedade dos agentes públicos. Ela também atua como um veículo de transparência. 
em geral, e (ii) institucional ou relacional, por meio de uma interferência mais direta nas atribuições dos demais Poderes. Em ambas as situações, deposita-se nos juízes uma missão que vai além do dever clássico de aplicar o direito a disputas subjetivas ou normativas e moderar os excessos dos outros ramos, podendo isso se verificar na Jurisdição constitucional e na ordinária, tanto coletiva quanto individual, bem como em várias dimensões práticas de operação do direito (SALLES, 2021).

Todavia, não costuma sercientífico o parâmetro utilizado para a aferição cotidiana de eventual Ativismo nas decisões judiciais.As análises não se baseiam em conceitos jurídicos aplicados a estudos de caso, mas em opiniões que circulam em redes sociais e espelham a maior ou menor simpatia de parcela da opinião pública sobre o tema. É preciso, no ponto, cuidado para filtrar situações de uso ideológico e manipulatório do termo, ocorridas quando aqueles que objetivam conter os poderes dos juízes ou reter o controle de legalidade utilizam-no, sem bases adequadas, como discurso para frear a magistratura (ACCATTATIS, 2008, p. 88), adjetivando como Ativismo algo que configura o mero adimplemento de funções jurisdicionais.

Quando efetivamente configurada, a postura ativista atrai inúmeros questionamentos acerca da legitimidade democrática. Aos juízes não cabe função governativa, tampouco a pura e simples invenção do direito. Compete-lhes, pelo contrário,enunciar ou reforçar os valores fundamentais apreendidos dentro da estrutura constitucional, legal ou jurisprudencial do regime democrático no qual operam. Assim, alude-se a algo como um dever metodológico de os juízes pensarem com as suas cabeças, com as cabeças dos outros e de modo coerente ao direito (CHIODI, 1996, p. 44-45). Atuar para além ou diversamente disso pode provocar, a médio prazo e a depender da intensidade, a erosão da imagem dos juízes como agentes técnicos, neutros e apolíticos (SHAPIRO, 1995, p. 62), criando, ainda, risco de retaliações da opinião pública e do sistema político.

Se o Ativismo Judicial rotineiro não é adequado como pauta de atuação à magistratura, tampouco é aceitável generalizar a filosofia da Autocontenção. Esta se reflete numa tendência jurisdicional oposta ao Ati- 
vismo, nos planos (stricto sensu) (i) interpretativo ou aplicativo e (ii) institucional ou relacional, notabilizada por atitudes judiciais de prudência e deferência às escolhas políticas dos demais ramos, manifestadas no judicial review e na judicação ordinária, coletiva ou individual, aí compreendidas as inúmeras dimensões da prática jurídica (SALLES, 2021). Embora Autocontenção não seja sinônimo de uma magistratura mortificada, apagada, ausente, indiferente ao direito e aos princípios (SHAPIRO, 2002, p. 165) e curvada a normas extremamente injustas (RADBRUCH, 1959, p. 112-113)7, nem sempre o contexto histórico, social e jurídico será compatível com uma postura de deferência à política em detrimento das normas constitucionais abertas ou principiológicas.

Ativismo e Autocontenção não se submetem a vereditos absolutos. Ambos enfrentam seus dramas, devendo os juízes equilibrarem-se nas virtudes e nos defeitos dessas faces gêmeas da função judicial (BARAK, 2006, p. 271 e 278-281). Em certos conflitos ou períodos históricos, o comportamento ativista pode mostrar-se adequado; em outros, a contenção talvez se mostre mais acertada. Porém, em qualquer situação, não devem os magistrados decidir por intuição (BARAK, 2006, p. 263 e 308), senão ter em mente os parâmetros teóricos que balizam a divergência e decidir consciente e fundamentadamente, após tudo sopesado.

O conjunto das mudanças no papel clássico dos juízes vai além. Ele tende a agregar à função de julgar atribuições gerenciais, misteres conciliatórios e, para alguns, até terapêuticos, como as constelações familiares, além de imersões tecnológicas, análises jurimétricas e supervisões sobre atos produzidos por algoritmos. Todavia, quanto mais o juiz administra, menos tempo dispõe para ler as petições, refleti-las, avaliar os aspectos da lide e confeccionar sentenças, lembrando-se que "Ler, pensar e escrever são, portanto, os aspectos essenciais da sentença como fato" (COUTURE, 1946, p. 202-203). Quanto mais incentiva procedimentos conciliatórios, negociativos ou terapêuticos, menos entoa as normas vigentes, menos reforça os padrões de legalidade e menos

7. O registro relaciona-se à clássica fórmula da injustiça extrema de Gustav Radbruch. 
promove a segurança jurídica, desligando-se da estatalidade e da lei para incorporar procedimentos de ordem privatística, práticas sociais e barganhas (CHIODI, 1996, p. 40-41).Quanto mais automatiza atos ou supervisiona algoritmos, na necessária busca por estatísticas e eficiência, mais mecaniciza e desumaniza o direito, incorpora processos opacos de tomada de decisão e reproduz precedentes de modo irrefletido (SALLES, 2020, p. 89).

Todas essas mudanças, embora ostentem pontos positivos e possam conviver com a Jurisdição propriamente dita, apresentam algumas complicações e não têm o efeito de se sobrepor a ela ou desmerecê-la, persistindo o ato de julgar como o carro-chefe e a prioridade da atividade jurisdicional.

Inúmeros desafios, enfim, movem-se na esteira dos novos tempos. Para enfrentar tais desafios, inexiste um roteiro. As reflexões acima servem como algumas diretrizes soltas que priorizam uma atuação técnica, criteriosa e ponderada dos juízes. A ideia subjacente a todas elas remete, ainda, à mediania aristotélica de que a virtude está no meio termo (ARISTÓTELES, 1991, p. 36) ${ }^{8}$, na harmonia entre os extremos, na busca pelo equilíbrio refletido na balança, que simboliza a equação entre castigo e culpa, entre lei e justiça, entre direitos e deveres, entre novo e antigo, ao lado de tantas outras dicotomias.

\section{CONCLUSÃ̃}

Os movimentos do Acesso à Justiça, a Judicialização, as interações nas Sociedades Complexas, a crise do Positivismo Jurídico, o Ativismo e a Autocontenção Judiciais, os percalços quantitativos dos sistemas de justiça, os impactos na atuação cotidiana dos juízes e outros são fenômenos ricos que envolvem a magistratura em uma série de encru-

8. "Ora, a virtude diz respeito às paixões e ações em que o excesso é uma forma de erro, assim como a carência, ao passo que o meio-termo é uma forma de acerto digna de louvor; e acertar e ser louvada são características da virtude. Em conclusão, a virtude é uma espécie de mediania, já que, como vimos, ela põe a sua mira no meio termo". 
zilhadas contemporâneas, incrementando as dificuldades da função jurisdicional.

Sem qualquer pretensão de fornecer roteiros ou lições, pode revelar-se útil, todavia, compartilhar algumas reflexões sobre o exercício da Jurisdição no atual quadro. Escapando um pouco do rigor metodológico e dos limites assinalados às considerações finais, passa-se doravante, neste tópico conclusivo, não só a condensar as observações lançadas ao longo deste artigo, mas a sintetizá-las em formulações objetivas, já mais concretas e direcionadas.

Aos juízes da atual era abre-se, entre outras, a possibilidade de equilibrar-se entre os fatores destacados de modo a: (i) aplicar o direito sem inovações abruptas, concretizando normas e padrões jurídicos construídos ao longo dos anos, modernizados para o presente e projetados para o futuro; (ii) preencher vácuos normativos, quando necessário, com o cuidado de não atalhar pura e simplesmente a democracia, abstendo-se de usurpar atribuições legislativas e executivas; (iii) lidar com normas constitucionais e princípios de maneira criteriosa, técnica e fundamentada, não os tratando como um freepass para a discricionariedade; (iv) balancear a permanente tensão entre segurança jurídica e justiça, cientes de que a fuga do direito legislativo ou jurisprudencial constitui medida excepcionalíssima; (v) observar os precedentes sem reduzir a Jurisdição a níveis de redundância próprios de autômatos; (vi) conciliar independência judicial e liberdade decisória com a necessária organicidade do direito, fazendo uso parcimonioso de técnicas como distinguishing e overruling; (vii) ter consciência de que o direito não é um produto pronto e, ao mesmo tempo, não agir como o capitão dos mares desconhecidos ou o mentor da vanguarda iluminista; (viii) atingir eficiência sem descurar da singularidade dos casos, harmonizando padronização e individualização; e (ix) priorizar o ato de julgar sobre as demais atividades recentemente incorporadas à rotina judicial, as quais, ainda assim, podem ser aproveitadas de sua melhor forma.

Essas reflexões buscam promover uma atuação técnica, criteriosa, racional e ponderada dos juízes nos novos desafios presentes no ambiente democrático nos novos tempos. A ideia subjacente a todas elas remete, 
ainda, ao equilíbrio traduzido na balança da justiça, antiga simbologia que permanece valiosa, mesmo com transformações milenares.

\section{REFERÊNCIAS}

AFONSO DA SILVA, José. Aplicabilidade das normas constitucionais. 3. ed. São Paulo: Malheiros, 1998.

ALEXY, Robert. Constitucionalismo discursivo. Tradução e organização de Luís Afonso Heck. 4 ed. Porto Alegre: Livraria do Advogado, 2015.

ALEXY, Robert Teoria dos direitos fundamentais. Tradução de Virgílio Afonso da Silva. SãoPaulo:Malheiros,2008, Título original: Theorie der Grundretche.

ACCATTATIS, Vincenzo. Governo dei giudici e giudici dei governo.7. ed. Franco Angeli: Milano, 2008.

ALLARD, Julie; e GARAPON, Antoine. Os juízes na mundialização: a nova revolução do direito. Lisboa: Instituto Piaget, 2005. Título original: Les Juges Dans La Mondialisation.

ARISTÓTELES. Ética a nicômaco. Tradução de Leonel Vallandro e Gerd Bornheim da versão inglesa de W. D. Ross. 4ed. São Paulo: Nova Cultural, 1991 (E-book). Disponível em: https://abdet.com.br/site/ wp-content/uploads/2014/12/\%C3\%89tica-a-Nic\%C3\%B4maco.pdf. Acesso em: 26 jan. 2021.

ATIENZA, Manoel. Curso de argumentación jurídica. Madrid: Trotta, 2013 .

BARAK, Aharon. The judge in a democracy. New Jersey: Princeton University Press, 2006.

BARROSO, Luis Roberto; MELLO, Patrícia Perrone Campos. O papel criativo dos tribunais - técnicas de decisão em controle de constitucionalidade. Revista da AJURIS, Porto Alegre, v. 46, n. 146, p. 295-334, jun/2019. 
BOBBIO, Norberto. O positivismo jurídico: noções de filosofia do Direito. Tradução de Márcio Pugliesi, Edson Bini e Carlos E. Rodrigues. São Paulo: Ícone, 1995. Título original: Il Positivismo Giuridico.

BRASIL. Conselho Nacional de Justiça. Justiça em Números 2020: ano-base 2019. Brasília: CNJ, 2020. Disponível em: https://www.cnj. jus.br/wp-content/uploads/2020/08/WEB-V3-Justi\%C3\%A7a-em-N\%C3\%BAmeros-2020-atualizado-em-25-08-2020.pdf. Acesso em: 10 jan. 2021.

CAPPELLETTI, Mauro. Accesso Allágiustizia: conclusionedi um progetto Internazionale diricercagiuridico-sociologica. Il Foro Italiano. Roma: Societa Editrice Del Foro Italiano, v. 102, p. 53-60, 1979.

CÁRCOVA, Carlos Maria. Direito, política e magistratura. São Paulo: LTr, 1996.

CERETTI, Adolfo; e GIASANTI. Prefazione. In: LIBERATI, Edmondo Bruti; CERETTI, Adolfo; GIASANTI, Alberto. Governo dei giudici:la magistratura tradiritto e politica. Milano: Giangiacomo Feltrinelli editore, 1996.

CHIODI, Giulio M. Giurisdizioneedequitáregolativa. In: LIBERATI, Edmondo Bruti; CERETTI, Adolfo; GIASANTI, Alberto. Governo dei giudici:la magistratura tradiritto e politica. Milano: Giangiacomo Feltrinelli editore, 1996. p. 31-48.

COUTURE, Eduardo J. Fundamentos do direito processual civil. Tradução de Rubens Gomes de Souza. São Paulo: Saraiva e Livraria Acadêmica: 1946. Título Original: Fundamentos Del Derecho Procesal Civil.

DWORKIN, Ronald. Levando os direitos a sério. Tradução de Nelson Boeira. São Paulo: Martins Fontes, 2011. Título original: Taking Rights Seriously.

DWORKIN, Ronald. O Império do direito. Tradução de Jefferson Luiz Camargo. Revisão técnica de Gildo Sá Leitão Rios. 2. ed. São Paulo: Martins Fontes, 2007. Título original: Law’s Empire. 
EUROPEAN COMMISSION FOR THE EFFICIENCY OF JUSTICE- CEPEF. European judicial systems: efficiency and quality of justice, an overview. Edition 2014 (2012 data). Disponível em: https:// rm.coe.int/european-judicial-systems-edition-2014-2012-data-efficiency-and-qualit/1680785d95. Acesso em: 29 nov. 2018.

FRIEDMAN, Lawrence M. The republic of choice: law, authority and culture. Cambridge-Massachusetts: Harvard University Press, 1994.

GARAPON, Antoine. O guardador de promessas: justiça e democracia. Tradução de Francisco Aragão. Lisboa: Instituto Piaget, 1998. Título original: Le Garden dês Promesses.

GUEDES, Armando Marques. A morosidade da justiça em Portugal. In: RIBEIRO, Manuel de Almeida (coord). Um debate sobre a morosidade da justiça. Coimbra: Almedina, 2009. p. 35-50.

HABERLE, Peter. Hermenêutica constitucional. A sociedade aberta dos intérpretes da Constituição: contribuição para a interpretação procedimental e pluralista da Constituição. Tradução de Gilmar Ferreira Mendes. Porto Alegre: Sérgio Antônio Fabris, 2002, especificamente as p. 12-13, 36, 41, 46-47 e 55. Título original: Die offeneGesselschaft Der Verfassungsinterpretem. Ein Beintragzur Pluralistischenund 'prozessualen'Verfassungsinterpretation.

HAZARD JR., Geoffrey C. Costo i durata del processo civile in Italia e in U.S.A. La durata eccessiva del processo: verso nuove promesse. Rivista didiritto civile, v. 32, Parte Prima. Padova: CEDAM - Casa Editrice Dott. Antonio Milani, 1986, ano XXXII, p. 271-284.

HESSE, Konrad. A força normativa da constituição. Tradução de Gilmar Ferreira Mendes. Porto Alegre: Sério Antonio Fabris, 1991. Título original: Die normative Kraft der Verfassung.

KELSEN, Hans. O que é justiça?. a justiça, o direito e a política no espelho da ciência. Tradução de Luís Carlos Borges. 3ed. São Paulo: Martins Fontes, 2001. Título original: Whatis justice? 
LEAL, Mônia Clarissa Henning. Jurisdição constitucional aberta: reflexões sobre a legitimidade e os limites da jurisdição constitucional na ordem democrática. Uma abordagem a partir das teorias constitucionais alemã e norte-americana. Rio de Janeiro: Lúmen Júris: 2007.

NONET, Philippe; SELZNICK, Philip. Direito e sociedade: a transição ao sistema jurídico responsivo. Tradução de Vera Ribeiro. Rio de Janeiro: Revan, 2010. Título original: Law andsociety in transition: towardsresponsivelaw.

PASOLD, Cesar Luiz. Metodologia da pesquisa jurídica: teoria e prática. $13^{\mathrm{a}}$ ed. rev. atual. ampl. Florianópolis: Conceito Editoral, 2015.

RADBRUCH, Gustav. Introduzione Alláscienza Del diritto. Tradizionedi Dino Pasini e Carlo A. Agnesotti. Torino: G. Giappichelli Editore, 1959. Titolooriginale: Einführung in die rechtswissenschaft.

RADBRUCH, Gustav, na Propedeutica Allá filosodia Del diritto. Traduzionedi Dino Pasini e Carlo A. Agnesotti. Torino: G. Giappichelli Editore, 1959. Titolooriginale: Vorschule der rechtsphilosophie.

ROOSEVELT III, Kermit. The myth of judicial activism: making sense of Supreme Court decisions. New Haven: Yale University Press, 2006.

SALLES, Bruno Makowiecky. Acesso à justiça e equilíbrio democrático: intercâmbios entre civil law e common law. v. 1. Belo Horizonte: Dialética, 2021.

SALLES, Bruno Makowiecky. Acesso à justiça e equilíbrio democrático: intercâmbios entre civil law e common law. v. 2. Belo Horizonte: Dialética, 2021.

SALLES, Bruno Makowiecky. Acesso à justiça na era da judicialização. Revista do CEJUR/TJSC: Prestação Jurisdicional, v. IV, n. 01, p. 277-305, dezembro 2016. Disponível em: https://revistadocejur.tjsc. jus.br/cejur/article/view/148. Acesso em: 10 jan. 2021. 
SALLES, Bruno Makowiecky. Jurisdição e inteligência artificial. Revista da Escola Judiciária do Piauí, Teresina, PI, Vol.2, n .2, p. 70-95, jul/dez, 2020. Disponível em: http://www.tjpi.jus.br/revistaejud/index. php/escolajudiciariapiaui/article/view/68. Acesso em: 10 jan.2021.

SHAPIRO, Martin. The success of judicial review and democracy. In: SHAPIRO, Martin; SWEET, Alec Stone. On laws, politics \& judicialization. New York: Oxford University Press, 2002. p. 149-183.

SHAPIRO, Martin. The United States In: TATE, C. Neal; VALLINDER, Torbjörn (org). The global expansion of judicial power. New York: New York University Press, 1995. p. 43-66.

SEGADO, Francisco Fernández. El tribunal constitucional español como legislador positivo. Pensamiento constitucional. Año XV, n. 15 . p. 128.2011.

SUNSTEIN, Cass R. One case at a time: judicial minimalism on The Supreme Court. Second Printing. Cambridge: Harvard University Press, 2001.

TATE, C. Neal. Why the expansion of judicial power? In: TATE, C. Neal; VALLINDER, Torbjörn (org). The global expansion of judicial power. New York: New York University Press, 1995. p. 27-38.

UNITED STATES COURTS - USC. Statistical tables for the federal judiciary. 2018. Disponível em: http://www.uscourts.gov/statistics-reports/statistical-tables-federal-judiciary-june-2018. Acesso em: 29 nov. 2018.

VALLINDER, Torbjörn. When the courts go marching in. In: TATE, C. Neal; VALLINDER, Torbjörn (org). The global expansion of judicial power. New York: New York University Press, 1995. p. 13-26.

ZAGREBELSKY, Gustavo. El derechodúctil.ley, derechos, justicia. Tradução de Marina Gascón. Madrid: Trotta, 2003. Original: Il DirittoMitte: legge, diritii, giustizia. 
ZANON JÚNIOR, Orlando Luiz. Teoria complexa do direito. 2. ed. rev. ampl. Curitiba: Prismas, 2014.

Recebido em: 01/06/2021

Aprovado em: 05/07/2021 